\title{
Online Payment and Consumers' Attitude towards Risk reduction strategies in a cash based economy
}

\author{
Ofunre C. Iriobe \\ Redeemer's University, Ede Osun state
}

\begin{abstract}
Online payment for goods has grown globally; unfortunately, the advancement in technology has not lowered the level of perceived risk felt by customers who pay for products online. The adoption of online payment in Nigeria is still low hence, consumers are given options considered less risky to use. Many online vendors have adopted different risk reducing strategies to help curb the perceive risk felt by customers when paying online. The effect of these risk reducing factors have not been adequately investigated in Nigeria especially, given that online vendors in Nigeria accommodate buying online and paying cash. Using a sample of 170 young people in Nigeria, an ordered logistic regression was used to test the relationship between various risk-reducing strategies such as Money Back Guarantee (MBG), Electronic Word of Mouth (EWOM), Informational Influence (IIF) and Pay on Delivery (POD) in Nigeria and customers' attitude towards electronic payment (CAT). We found that MBG, EWM and POD have significant positive influence on (CAT) while IIf exhibited a significant negative influence. The various risk reduction strategies employed by the study contributes a significant $12 \%$ to the variation of customers' attitude towards electronic payment. We concluded that risk reduction strategies have a significant positive impact on customers' attitude towards electronic payment in Nigeria. Hence, we recommend that online vendors should encourage more interpersonal online interaction among users, they should also provide more money back guarantees and pay-on-delivery offers to consumers to simulate and hasten their movement from traditional payment methods to online payment methods.
\end{abstract}

Keywords: Online Shopping, Money Back Guarantee, Electronic Word of Mouth, Informational Influence, Pay on Delivery, Customers' attitude towards electronic payment

Word Count: 249

\section{INTRODUCTION}

Online payment for goods has grown globally with the rapid improvements in technology and the development of the internet. Unfortunately, the advancement in technology, especially payment technology has not lowered the level of perceived risk felt by customers when paying for products online or the negative factors that co-exist with the benefits of online payment (Vos et al, 2014; Liebermann \& Paroush, 1982). Forsythe and Shi (2003) argued that technology has simply encouraged people to use the internet more for other purposes than for online shopping or payment. Consumers use the internet to search for product or price information or general information, social media engagement etc. The adoption of technology for payment online in developing countries is still low hence, even when it is available, consumers are given options to choose which payment instrument they feel more comfortable with, and consider less risky to use (Karoubi, Chenavaz \& Paraschiv, 2016). In Nigeria, the option of paying cash after shopping online is provided also.

In choosing a payment instrument, users' perceptions of risk in e-commerce transactions play a key role (Cheng, Ab Hamid, \& Cheng, 2011). For instance, uncertainties faced by consumers either in form of financial loss, product performance expectations or even security breaches in online payments increases the perceived risk faced by customers when compared to 
traditional payment methods (Hamid \& Cheng, 2013). Even among various online payment methods, the risk to use each varies and consumers consider this when deciding on which website or payment method to use (Bart, Sultan \& Urban, 2005).

This study is primarily motivated by the various risk reduction methods adopted by vendors to encourage online shoppers in Nigeria to pay online. Nigeria has a high rate of unbanked people, and transactions are heavily cash-based (Central Bank of Nigeria (CBN) 2011a). In Nigeria, online shoppers are given the option of paying online, paying with cash or pay with other electronic forms after the purchased item has been delivered. These options were provided basically to reduce the risk perceived by online shoppers, and to make up for users who have internet access but no bank account. Three factors make shopping online in Nigeria challenging. One, there is a high number of poor income earners who don't have bank accounts (Ejiofor \& Rasaki, 2012; Olajide, 2012; Central Bank of Nigeria (CBN) 2011a), and secondly, $90 \%$ of the transactions in Nigeria are cash based, and only $10 \%$ of the citizens engage in formal banking activities and thirdly, there is poor policies as well as poor infrastructure both financial and otherwise to sustain an e-commerce system (CBN 2011b).

The type of demographic characteristics that exist in developing nation's e-commerce industry fuels perceievd risk. It affects the growth of online shopping and limits the e-payment system (Karoubi et al, 2016; Hamid \& Cheng 2013). Although, Schuh and Stavins (2010) believes that payment characteristics are more significant in explaining consumer payment use, they noted that unbanked consumers depend heavily on cash transactions as against the consumers with bank accounts.

There has been extant discussion on risk and its effect on behaviour since 1960. Previous studies have examined consumers' attitude towards traditional and online payment channels (To, Papagiannidis \& Westland, 2014; Kollmann, Kuckertz, \& Kayser, 2012), and how perceived risk can be mitigated especially in the online environment. For instance, OECD (1999) suggested that provision be made for return of purchased product and as well as avoid overcharging, while Hamid and Cheng (2013) believed that ensuring adequate internal controls can help. Huang, Schrank, and Dubinsky (2004) studied the effect of brand names and brand loyalty on perceived risk of young shoppers and concluded that it has a positive effect. maZhu, Lee, and O'Neal (2011) believes that activities geared towards building trust could significantly reduce online consumer perceived risk during online shopping. Apart from identified risk reducing strategies, individual retailers are also on the lookout for ways to reduce perceived risk felt by consumers when paying for merchandize online (Hassan, Kunz, Pearson and Mohamed 2000; Yaqub, Bello, Adenuga, and Ogundeji 2013).

In Nigeria, the effect of the various risk-reduction strategies on consumers' decision to pay online have not been given adequate attention as well as how consumers respond to these risk reduction strategies or their attitude towards electronic payment have not been duly investigated. There is need for this study because understanding what relieves online risk in a an environment with high internet access, but predominantly cash-based economy can help explain consumer's behaviour (Greatorex \& Mitchell, 1994), and restore confidence in ecommerce transactions (Vos et al, 2014).

This study intends to explore the online payment system in Nigeria, and the effect selected risk reducing strategies have on consumers' attitude to use online payment channels for their shopping. There are many risk-reduction strategies identified in literature (Mitchell \& Greatorex 1993; Derbaix 1983; Roselius 1971), but this study will focus on Electronic word of mouth, Money back guarantee, information on security (captured as informational influence) 
and pay-on-delivery because they are familiar strategies adopted by online vendors in Nigeria. This study is set out to answer two questions, what effect does each risk reducing strategy have on consumers attitude to pay online in Nigeria and what effect will demographic variables have on the relationship between risk reducing strategies and consumers' attitude towards electronic payment?

Although previous studies have examined the effect of perceived risk on online shopping behaviour (Hassan, Kunz, Pearson, \& Mohamed 2000; Soopramanien 2010; Cemberci, Civelek \& Sozer 2013) and studied e-payment from the technical and user acceptance perspectives (Teoh, Lin \& Chua, 2013), this study will examine the effectiveness of risk reducing strategies and how they mitigate the effect of risk on consumers in a cash-based economy.

\section{Electronic Payment System in developing nations}

\section{LITERATURE REVIEW}

Electronic payment system (EPS) is growing no doubt however, the concern about security and privacy is still the major reason why consumers are sceptical about adopting it (Clayton 2000). Even when they have strong positive attitude towards internet usage and e-commerce activities generally, accepting online payment technology still remains a challenge (Iriobe 2017). This is predominant in developing countries whose gains from e-payments are minimal and who still operate a cash-based economy. For instance, a report published by Visa Inc ${ }^{1}$., showed that about $\$ 983$ billion was added to the GDP of 56 countries between 2008 and 2012 . There was also an increase in consumption globally as a result of payments made through electronic cards alone (Zandi et al. 2013). This is an indication that the benefit of electronic payment goes beyond just convenience and safety of cards, it plays a role in economic growth of a nation and the world at large (Yaqub, Bello, Adenuga, \& Ogundeji, 2013).

The growth of Electronic payment system (EPS) in developing countries has received considerable attention. For instance, Brooks (2011) studied the institutional arrangement in developing an EPS. Musub et al, (2000) summarized the challenges of information System in Sub-Saharan Africa where inadequate infrastructure is lacking, e.g. poor power supply and telecommunication - they observed that there is much disparity between the rate of infrastructural growth, and technological change. Other studies outlined the advantages and limitations of EPS in Asia (Yu, Hsi, \& Kuo 2002), and the benefits of e-commerce to businesses in developing countries (Molla \& Heeks, 2007). Teoh, Chong, Lin \& Chua (2013), in their review, listed factors that affect consumers' perception of e-payment as popularity of cash, failure of system design to meet user requirements, security and lack of trust etc.

Nigeria has a peculiar situation when it comes to Electronic Payment System (EPS) considering its socioeconomic environment (Heeks, 2002; Avgerou, 2008). In spite of the growth, and the economic gains associated with electronic payments (Yaqub, Bello, Adenuga, \& Ogundeji, 2013).

Nigerian consumers are yet to embrace the electronic payment technology (Nwankwo \& Eze 2012). It is believed that lack of infrastructure is considered responsible for this (Brook, 2011) and even where it is adopted; it is often a combination of online payment and traditional payment methods. For example, consumers place orders online and they have the option to pay cash once the items are delivered. At an early stage of e-commerce development,

1Visa Inc. is an American multinational financial services corporation headquartered in Foster City, California, United States 
consumers are more interested in searching for more information than buying items online (Hamid \& Cheng 2013) because they lack knowledge on the likely outcome of their decision (March, 1978). Although EPS has replaced most attributes of the traditional payment systems like cheques (Liao \& Handa 2010), achieving a cashless society will continue to be a mirage in the long run (Tee \& Ong 2016). This is because risk averse customers are sceptical about using a new technology for their shopping or payments (Bhatnagar, Misra, \& Rao 2000).

The various outcomes affecting e-commerce especially e-payment are not peculiar to Nigeria alone, developed countries experience such as well (Datta 2012; Ariff, Sylvester, Zakuan, Ali \& Ismail, 2007) , even though the impact varies (Yu, His \& Kuo 2002).

\section{Perceived Risk}

Perceived risk is one of the constructs researchers have identified as a major influence on online shopping behavior (Hassan, Kunz, Pearson \& Mohamed, 2000; Soopramanien 2010; Cemberci, Civelek \& Sozer, 2013), and it is believed to be higher in the online environment when compared with the Offline stores (Salam, Rao \& Pegels, 2003).

The various definitions given to perceived risk are viewed with respect to uncertainty and consequences (Ross 1975; Cunningham 1967). Events that are uncertain and uncontrollable increases perceived risk, and consumers make effort to mitigate the effect of risk on their decisions online. For instance, new customers will search for relevant information that will help them reduce risk while buying online (Challappa \& Pavlon, 2002; Hamid \& Chen, 2013), vendors as well as regulators also attempt to put in place risk reducing strategies to aid consumers make decision to pay for goods bought online (Kim 2001,). In spite of the efforts to lower perceived risk, issues of security and privacy is still top concern for consumers who want to pay online (Clayton 2000), and these affects consumers' buying decision negatively by increasing perceived risk (Li\& Huang 2009).

Li and Huang (2009) reported that online shopping is perceived as a higher risk or loss by consumers, and they believe that risk-averse consumers are less likely to shop on the internet because products cannot be examined physically, and there is high tendency that what appeared on the screen may differ from the physical item delivered. The effect that perceived risk has on purchasing behaviour is universal (Ariff, Sylvester, Zakuan, Ali \& Ismail, 2007), andfor a developing nation like Nigeria, and where online shopping is relatively growing, the lack of basic support infrastructure increases the level of perceived risk faced by customers (Li\& Huang 2009) hence, there is need to provide measures to lower perceived risk by customers. Although other factors may influence risk such as personal characteristics (e.g., gender, numeracy, political or cultural views), confidence in those managing the risk (e.g., first responders, local officials), and belief in one's ability to cope with the adverse event, this cannot be compared to lack of infrastructure. Even when a customer is willing to pay online, such willingness is hampered by poor infrastructure. This is part of the reasons why online stores in Nigeria introduced pay-on-delivery method to deal with perceived risk in an economy that is cash-based.

\section{Reducing Perceived risk}

One of the guiding principles for engaging in e-commerce activities as recommended by OECD is that payment mechanisms should be easy to use, and there should be appropriate security for any payment risk consumers may likely face. In dealing with perceived risk of new customers, Roselius, (1971) suggested that it is important to identify the type of risk customers are facing, and then address such using the appropriate risk reduction strategy. Roselius further proposed strategies that can be used to reduce perceived risk regarding among other 
things money loss. Other researchers like Derbaix (1983) also suggested Money-back guarantee, Store Image, Advice of friends and relatives, Salesman's advice etc, and recently, Mitchell and Greatorex (1993) with a combination from other studies, proposed about 14 different strategies for reducing perceived risk. Akaah and Korgaonkar (1988) investigated the relative importance of 8 risk reduction strategies on direct marketing, and concluded that Money-back guarantee is the most important to consumers. It is important to point out that studies on perceived risk reduction methods are not conclusive yet (Kim 2007). There is no consensus on the order of importance of these strategies (Zheng et al 2012). Moreover, the focus of past researchers on perceive risk have always been on products categories (Samadi and Yaghoob-Najadi 2009; Soopramanien et al. 2007), brick and mortal/online shopping (Vos et al 2014.; Akaah \& Korgaonkar 1988; Derbaix 1983; Roselius 1971) and few have worked on risk reduction when it comes to electronic payment system (Zheng et al 2012; Cheng 2013).

Risk reduction strategies are categorized into personal and non-personal risk reduction strategies (Kim 2010), although researchers have not agreed on the category preferred by consumers (Zheng et al 2012), a report by eMarketers however showed that comsumers will likely pay for transaction online if the security of their transaction is guaranteed. Salam, Rao, and Pegels (2003) identified contractual agreement as a form of reducing risk. Social media platform is another means retailers can use to lower the perceived risk of consumers through constant interaction (Leeraphong \& Mardjo 2013). Consumers can be convinced to buy online if the retailer maintains a good relationship, and other members of the online community give a good review about their experiences. This will help build trust and reduce risk. At the inception of a threatening situation, perceived risk tends to be higher however, as measures are taken to address the crisis, there is a decrease in perceived risk and people eventually adjust to the situation (Burns, Peters \&Slovic 2007). Based on this, it is proposed that:

\section{Hypotheses}

\section{Pay-on-delivery}

Pay on delivery is a relatively new risk reliever used by online vendors in Nigeria. This method allows consumers to physically examine the product they intend to buy physically before payment is made through electronic transfer or POS devices. The strategy was use to mitigate risk of online shoppers who were not comfortable making payments online. Not much work has been done on this, but few studies that surveyed consumers' opinion on pay-on-delivery method showed that it is effective in influencing consumers to try online buying. Hence, it is proposed that

Hypothesis: Pay-on-delivery has a significant effect on consumers' attitude to pay for items online.

\section{Money back Guarantee (MBG)}

Money back guarantee is not just a post purchase marketing instrument, but it is also used to protect consumers from perceived risk of money loss. This method allows consumers to try out a purchased item to determine suitability or return it within a specified time. The grace period given for a product to be tried out is also considered a factor in evaluating the effectiveness of money-back guarantee (Yanhong, Zilberman \& Heiman, 2014)

Money back Guarantee (MBG) has a significant effect on consumers' attitude to pay for items online 


\section{Electronic Word of Mouth}

Kwahk and Ge (2012) reported that $70 \%$ of consumers visit social media websites such as message boards, social networking sites and blogs to get information on a company, brand or product and about $49 \%$ of these customers make a purchase decision based on information gathered from social media sites. Yoo et al 2015 were of the opinion that EWOM is an effective marketing tool for e-commerce sites, and it is necessary for maintaining customer confidence in the customer-to-customer e-business. Reviews from social media are highly trusted because they are real experiences from real people who are independent. It is therefore proposed that

\section{Electronic Word of Mouth has a significant effect on consumer's attitude to pay for items online}

\section{Informational Influence}

The availability of information on the intended product consumers want to buy, the privacy and security level of the payment system influences customers' attitude toward online risk (Ranganathan \& Ganapathy 2002). Electronic payment involves more risk than traditional payment system, and customers knowledge about the new risk they are about to face and the measures put in place to deal with such risk play a role in mitigating the effect of the risk (Mitchell, 1999). It is therefore proposed that:

\section{Informational influence has a significant effect on consumers' attitude to pay for items online}

\section{RESEARCH METHOD}

This empirical study utilizes a survey research method to collect data, to explain the influence of risk reduction strategies on consumers' attitude towards online payment in Nigeria.

The population of the study comprised of customers who make online payment in Nigeria. While the figure for customers who pay online in Nigeria may not be readily available, the Nigerian Communication Commission put the figure of internet subscribers at 136 million as at September 2017.

An online questionnaire was sent out to active internet users via social media platforms (Facebook and WhatsApp chat groups). Young people make up majority of adults population who are actively engaged online, and a large chunk of this number are students (Lenhart 2009; Ellison et al. 2007). Young people are deemed as an appropriate target for sampling purpose because they are active online shoppers and are frequent online buyers (Mangold \& Faulds, 2009). In total, 516 online questionnaires were sent out, and 285 responses returned.

All respondents were expected to have a credit/debit card or any other online payment instrument that is acceptable in Nigeria to qualify to be included in the study. Two, they must be conversant with e-commerce activities in Nigeria. Of the total 285 questionnaires returned, 115 were insufficiently or erroneously completed. A final sample size of 170 questionnaires was deemed adequate for the purposes of this exploratory study. The study's overall response rate was 33 percent in terms of the number of completions and the number of people approached and requested to participate.

Key constructs for the study were adopted and modified from previous studies to investigate the effect of risk reducing strategies on consumers' attitude to pay online. A multi-item measurement scale with five-point Likert-style responses ranging from 1 = "strongly disagree," through 3 = "neutral," to 5 = "strongly agree" was used to measure the variables. 
Drawing from the measures of risk reducing strategies used in previous studies (Flynn et al. 1996; Sun et al. 2006), risk-reducing strategies in e-payment platforms was operationalized with three specific variables: Pay-on-delivery, Money back guarantee and Electronic word-ofmouth.

Preliminary analyses were conducted to provide information about the characteristics of sample respondents, including gender, age, and the preferred platform used for payment. Correlation was used to test for the linear associations of the risk reduction strategies while regression was used to test the relationship between the dependent and independent variables.

\section{Independent Variables}

The questionnaire contained questions on the various methods of risk reducing methods used in Nigeria. Risk reducing methods was measured using pay-on-delivery, money back guaranty and electronic word-of-mouth. These were operationalized with questions measured in a fivepoint likert scale from (1), "strongly disagree", (2), "Disagree", (3), "neutral", (4), "Agree" and (5), "strongly agree"

\section{Dependent Variable}

A structured quantitative questionnaire was developed to test the attitude of consumers towards online payment methods. Attitude was operationalized using four question items measured in a five-point likert scale from (1), "strongly disagree", (2), "Disagree", (3), "neutral", (4), "Agree" and (5), "strongly agree"

\section{Models}

The hypotheses for this study will be tested using ordered logistics regression. The equation for these models is as follows:

\section{RESULTS}

\section{Demographic Characteristics of the Respondents}

The socio-economic characteristics of the respondents that participated in the Online Payment survey are presented in Table 1 below. 
TABLE 1: Respondents' Demographic Characteristics

\begin{tabular}{|c|c|c|c|}
\hline Variables & Respondents' Grouping $(n=170)$ & Frequency & Percent \\
\hline \multirow{2}{*}{ Use } & Yes & 156 & 94.55 \\
\hline & No & 9 & 5.45 \\
\hline \multirow{3}{*}{ Gender } & Male & 64 & 38 \\
\hline & Female & 106 & 62 \\
\hline & $18-25$ & 63 & 37.06 \\
\hline \multirow{3}{*}{ Age } & $25-35$ & 78 & 45.88 \\
\hline & $36-45$ & 15 & 8.82 \\
\hline & Above 45 & 14 & 8.24 \\
\hline \multirow{2}{*}{ Marital Status } & Married & 54 & 31.76 \\
\hline & Single & 116 & 68.24 \\
\hline \multirow{4}{*}{ Education status } & WAEC & 3 & 1.76 \\
\hline & Undergraduate & 34 & 20.01 \\
\hline & B.Sc/HND & 96 & 56.47 \\
\hline & Post Graduate & 37 & 21.76 \\
\hline \multirow{5}{*}{ Income } & Below 50,000 & 56 & 32.94 \\
\hline & $51,000-100,000$ & 32 & 18.82 \\
\hline & $101,000-150,000$ & 30 & 17.65 \\
\hline & $151,000-200,000$ & 18 & 10.59 \\
\hline & Above 200,000 & 34 & 20.00 \\
\hline \multirow[b]{5}{*}{ Frequency } & At least once a month & 58 & 34.12 \\
\hline & Once in two months & 38 & 22.35 \\
\hline & I have shopped only once & 23 & 13.53 \\
\hline & I want to, but it's too risky & 17 & 10.00 \\
\hline & I shop always & 34 & 20.00 \\
\hline
\end{tabular}

Source: Field Survey, 2018

As shown in Table 1, 95\% of the respondents have made payments online using POS, ATM, and Quick Teller in Nigeria and only about 6\% of the respondents have not made use of online payment during the study period. The gender profile of the respondents also reveals that 38\% are male while $62 \%$ are female. There is a gap between these two values, which may suggest that gender has significant influence on the use of online payment. The age profile of the respondents depicts that many of the respondents (45.88\%) were in the age category of 25 35 years, $37.06 \%$ were in the category of 18- 25 years of age, followed by the respondents in the age category $36-45$ years (8.82\%) and $8.24 \%$ were in the bracket of above 45 years. The results of the age distribution show that most of the users of online payment platforms are youths (ages 18 - 35 years) and that the older respondents are less willing to take the risks associated with making online payments.

A larger percentage of the respondents in the survey are single (68.24\%), while the married accounted for $31.76 \%$. This is in agreement with the age profile of the respondents, where we have the largest percentage to be youths. Besides, youths are known to take more risks and more technologically inclined than married adults. A married adult will normally weigh options available, and probably consider the well-being of his dependents before taking any risk. Interestingly, the table also shows that most of the respondents are highly educated and thus well informed on the use of online payment platforms, with $56.47 \%$ having B.Sc./HND degrees, $21.76 \%$ with Post Graduate degrees and 20.01\% were undergraduates. Only 1.76\% of the respondents have (WAEC) high school certificates. However, the distribution of the income 
status of the respondents reveals that most of the participants have an income of less than $\$ 50,000$ (32.94\%) followed by those who have an income of above $\$ 200,000$, then those within the income range $\$ 51,000$ - $\$ 100,000$ (18.82\%). Those within the income range of $\$ 101,000$ - $\$ 150,000$ accounted for $17.65 \%$, while the remaining $10.59 \%$ represents those within the income $\mathrm{N} 151,000$ - $\mathrm{N} 200,000$. The disparity in the income distribution could be as a result of undergraduate students who participated in the survey.

\section{Prioritization of Risk Reduction Strategies Influencing Customers' Attitude towards Online Payment}

Table 2 presents the mean and the standard deviation of some of the risk reduction strategies influencing customers' towards online payment in Nigeria. The results showed the risk reduction strategies in order of importance with respect to their means and standard deviations.

TABLE 2: Risk Reduction Strategies

\begin{tabular}{|l|l|c|l|}
\hline S/N & Factors & Mean (M) & Standard Deviation (SD) \\
\hline 1 & Pay on Delivery & 4.1353 & 0.8834 \\
\hline 2 & Money Back Guarantee & 3.7118 & 0.9817 \\
\hline 3 & Electronic Word of Mouth & 3.1647 & 1.0697 \\
\hline 4 & Information Influence & 3.1588 & 1.0789 \\
\hline
\end{tabular}

Source: Researcher's Computation, 2018

Pay on Delivery (POD) $(M=4.1353 ; S D=0.8834)$ ranking first, is the most influencing risk reduction strategy on customers' attitude towards online payment in Nigeria. This position is understandable given that Pay-on-delivery is less risky compared to other forms of risk reduction strategies, moreover, customers are expected to examine the products before making payments. Money Back Guarantee (MBG) $(M=3.7118$; $S D=0.9817)$ ranked second, implying that M B G is the second risk reducing strategy that influences customers' attitude towards online payment. In earlier studies, MBG has been identified as the most important risk reducing strategy (Akaah \& Korgaonkar 1998), in Nigeria it cannot be regarded as such.

The result showed that customers would likely prefer a method that is less risky in cash based economy. Electronic Word of Mouth (EWOM) is the third most influencing strategy on customers' attitude towards online payment ( $M=3.1647 ; S D=1.0697)$. This position is in line with earlier studies that identified information sharing among peers as vita to influencing customers' attitude towards an action (Yoo, Kim \&Sanders, 2015; Bruwer, Fong \& Saliba, 2013; Liaw, Zhu \& Lee, 2005). However, Information Influence (INFO) is the least influencing strategy employed to influence customers' attitude towards online payment $(M=3.1588 ; S D=1.0789)$. Unlike the study by Zheng et al (2012) who studied Chinese online shoppers and observed that information about a product was the most influencing risk reliever, in this study, information about online payment may not reduce much perceived risk felt by customers. This may be as a result of poor development of financial infrastructure coupled with low adoption of internet banking in Nigeria.

\section{Results of the ANOVA and Post Hoc Tests on Influence of Demographic Variables on Risk Reduction Strategies}

The effects of the demographic characteristics of respondents on risk reduction strategies influencing customers' attitude towards online payment is presented in this section. 


\section{Age and Risk Reduction Strategies}

Table 4 shows a one way ANOVA test between age and the four risk reduction strategies influencing customers' attitude towards online payment.

TABLE 3: Influence of Age on Risk Reduction Strategies

\begin{tabular}{|l|c|c|c|c|c|}
\hline Between groups & Sum of Squares & df & Mean Square & F & Sig. \\
\hline POD & 13.0389 & 3 & 4.3463 & 6.07 & 0.0006 \\
\hline MBG & 3.1458 & 3 & 1.0486 & 1.09 & 0.3551 \\
\hline EWOM & 0.8100 & 3 & 0.2700 & 0.23 & 0.8735 \\
\hline INFO & 4.2086 & 3 & 1.4029 & 1.21 & 0.3079 \\
\hline
\end{tabular}

Source: Researcher's Computation, 2018

The results of the ANOVA show that there is a statistical significant relationship between age and only one of the four risk reduction strategies; "POD" ( $F=6.07, p=0.0006)$, at $5 \%$ significance level. The remaining factors, "MBG" $(F=1.09, p=0.3551)$, "EWOM" $(F=0.23, p=$ $0.8735)$, and "INFO" ( $F=1.21, p=0.3079$ ) have an insignificant relationship with age.

To measure the strength of association (omega square, $\omega^{2}$ ) between age and pay on delivery since there is a significant $F$, from the one way analysis of variance on the effect of age on the four risk reduction strategies influencing customers' attitude towards online payment, the omega square is calculated as:

$$
\begin{aligned}
\text { Omega square }\left(\omega^{2}\right) & =\mathrm{SS}_{\mathrm{B}}-(\mathrm{K}-1) \mathrm{MS}_{\mathrm{W}} /\left(\mathrm{SS}_{\mathrm{T}}+\mathrm{MS}_{\mathrm{W}}\right) \\
& =13.04-(3-1) 0.7160 /(131.89+0.7160) \\
& =11.61 / 132.6060=0.086
\end{aligned}
$$

The results indicated that the independent variable (age) accounts for approximately 8.6\% of the variance in the dependent variable (pay on delivery) of the customers' attitude towards online payment in Nigeria.

Table 4: Dependent Variable: Pay on Delivery (POD)

\begin{tabular}{|lll|}
\hline Age & Mean & Std. Dev. \\
\hline $18-25$ & 4.2698 & 0.7871 \\
\hline $26-35$ & 4.2308 & 0.7194 \\
\hline $36-45$ & 3.8667 & 1.1255 \\
\hline Above 45 & 3.2857 & 1.3260 \\
\hline
\end{tabular}

\section{Source: Researcher's Computation, 2018}

The results in Table 4 from the summary of Scheffe's Post Hoc test indicate that respondents within the age range 18-25 mostly employed the pay on delivery strategy as against other online payment strategies with a mean of 4.27 , followed by respondents within the age range 26-35 with a mean of 4.23. This shows that Nigerian youth have more confidence in the pay on delivery platform for electronic purchases than any other platform.

\section{Gender and Risk Reduction Strategies}

Table 5 shows a one way ANOVA test between gender and the four risk reduction strategies influencing customers' attitude towards online payment. 
TABLE 5: Gender and Risk Reduction Strategies

\begin{tabular}{|l|c|c|c|c|c|}
\hline Between groups & Sum of Squares & df & Mean Square & F & Sig. \\
\hline POD & 0.3355 & 1 & 0.3355 & 0.43 & 0.5137 \\
\hline MBG & 1.8331 & 1 & 1.8331 & 1.91 & 0.1685 \\
\hline EWOM & 1.8281 & 1 & 1.8281 & 1.60 & 0.2072 \\
\hline INFO & 0.2510 & 1 & 0.2510 & 0.21 & 0.6438 \\
\hline
\end{tabular}

Source: Researcher's Computation, 2018

The results of the ANOVA above show that there is no significant relationship between gender and the four risk reduction strategies influencing customers' attitude towards online payment at $5 \%$ level of significance with "POD" $(F=0.43, p=0.5137)$, "MBG" $(F=1.91, p=0.1685)$, "EWOM" ( $F=1.60, p=0.2072)$, and "INFO" $(F=0.21, p=0.6438)$. This implies that the gender of customers has no relationship with the risk reduction strategy employed for online payments by Nigerian youth.

\section{Marital Status and Risk Reduction Strategies}

Table 6 shows a one way ANOVA test between marital status and the four risk reduction strategies influencing customers' attitude towards online payment.

Table 6: Marital Status and Risk Reduction Strategies

\begin{tabular}{|l|c|c|c|c|c|}
\hline \multicolumn{1}{|c|}{ Between groups } & Sum of Squares & df & Mean Square & F & Sig. \\
\hline POD & 5.5543 & 1 & 5.5543 & 7.39 & 0.0073 \\
\hline MBG & 0.0087 & 1 & 0.0087 & 0.01 & 0.9248 \\
\hline EWOM & 2.2503 & 1 & 2.2503 & 1.98 & 0.1615 \\
\hline INFO & 0.8439 & 1 & 0.8439 & 0.72 & 0.3961 \\
\hline
\end{tabular}

Source: Researcher's Computation, 2018

The results of the ANOVA show that there is a significant relationship between marital status and pay on delivery at $5 \%$ level of significance $(F=7.39 p=0.0073)$. However, there is no significant relationship between marital status and other risk reduction strategies.

To measure the strength of association (omega square, $\omega^{2}$ ) between marital status and pay on delivery since there is a significant $F$, from the one way analysis of variance on the effect of marital status on the four risk reduction strategies influencing customers' attitude towards online payment, the omega square is calculated as:

$$
\begin{aligned}
\text { Omega square }\left(\omega^{2}\right) & =\mathrm{SS}_{\mathrm{B}}-(\mathrm{K}-1) \mathrm{MS}_{\mathrm{W}} /\left(\mathrm{SS}_{\mathrm{T}}+\mathrm{MS}_{\mathrm{W}}\right) \\
& =5.55-(1-1) 0.7520 /(131.89+0.7520) \\
& =5.55 / 132.6420=0.042
\end{aligned}
$$

The results indicated that the independent variable (marital status) accounts for approximately $4.2 \%$ of the variance in the dependent variable (pay on delivery) of the customers' attitude towards online payment in Nigeria.

Table 7: Dependent Variable: Pay on Delivery

\begin{tabular}{|lll|}
\hline Marital Status & Mean & Std. Dev. \\
\hline Married & 3.8704 & 1.0648 \\
\hline Single & 4.2586 & 0.7590 \\
\hline
\end{tabular}

Source: Researcher's Computation, 2018 
The results in Table 7 from the summary of Scheffe's Post Hoc test indicate that single respondents employed the pay on the delivery strategy more than married respondents with a mean of 3.87. This shows that youths who are single mostly often use the pay on delivery platform for all e-commerce transactions in Nigeria.

\section{Educational Qualification and Risk Reduction Strategies}

Table 8 shows a one way ANOVA test between educational qualification of respondents and the four risk reduction strategies influencing customers' attitude towards online payment.

Table 8: Educational Qualification and Risk Reduction Strategies

\begin{tabular}{|l|c|c|c|c|c|}
\hline Between groups & Sum of Squares & Df & Mean Square & F & Sig. \\
\hline POD & 126.3630 & 3 & 1.8418 & 2.42 & 0.0680 \\
\hline MBG & 3.5783 & 3 & 1.1928 & 1.24 & 0.2959 \\
\hline EWOM & 6.3692 & 3 & 2.1231 & 1.88 & 0.1342 \\
\hline INFO & 2.3220 & 3 & 0.7740 & 0.66 & 0.5772 \\
\hline
\end{tabular}

Source: Researcher's Computation, 2018

The results of the ANOVA show that there is no significant relationship between the educational qualification of respondents and the four risk reduction strategies influencing customers' attitude towards online payment at 5\% significant level.

\section{Income and Risk Reduction Strategies}

Table 9 shows a one way ANOVA test between the income of respondents and the four risk reduction strategies influencing customers' attitude towards online payment.

TABLE 9: Income and Risk Reduction Strategies

\begin{tabular}{|c|c|c|c|c|c|}
\hline Between groups & Sum of Squares & Df & Mean Square & F & Sig. \\
\hline POD & 11.5612 & 4 & 2.8903 & 3.96 & 0.0043 \\
\hline MBG & 4.5661 & 4 & 1.1415 & 1.19 & 0.3173 \\
\hline EWOM & 2.5434 & 4 & 0.6358 & 0.55 & 0.6995 \\
\hline INFO & 7.3721 & 4 & 1.8430 & 1.61 & 0.1751 \\
\hline
\end{tabular}

Source: Researcher's Computation, 2018

The ANOVA results above reveal that there is a significant relationship between the income of respondents and the pay on delivery strategy for online payment; "POD" $(F=3.96, p=0.0043)$ at $5 \%$ significant level.

To measure the strength of association (omega square, $\omega^{2}$ ) between the independent variable and the dependent variable, since there is a significant $F$, from the one way analysis of variance of the effect of the income of respondent on the four risk reduction strategies influencing customers' attitude towards online payment, the omega square is calculated as:

$$
\text { Omega square } \begin{aligned}
\left(\omega^{2}\right) & =\mathrm{SS}_{\mathrm{B}}-(\mathrm{K}-1) \mathrm{MS}_{\mathrm{W}} /\left(\mathrm{SS}_{\mathrm{T}}+\mathrm{MS} \mathrm{S}_{\mathrm{W}}\right) \\
& =11.56-(4-1) 0.7293 /(131.89+0.7293) \\
& =9.3721 / 132.6193=0.071
\end{aligned}
$$

The results indicated that the independent variable (income) accounts for approximately 7.1\% of the variance in the dependent variable (pay on delivery) of the customers' attitude towards online payment in Nigeria. 
TABLE 10: Dependent Variable: Pay on Delivery

\begin{tabular}{|lll|}
\hline Income & Mean & Std. Dev. \\
\hline Below 50,000 & 4.3929 & 0.7053 \\
\hline $51,000-100,000$ & 4.1250 & 0.7513 \\
\hline $101,000-150,000$ & 3.8667 & 0.9371 \\
\hline $151,000-200,000$ & 4.4444 & 0.7838 \\
\hline Above 200,000 & 3.7941 & 1.0949 \\
\hline
\end{tabular}

Source: Researcher's Computation, 2018

The summary of Scheffe's post hoc range test was used to identify homogeneous subset of Income and its influence on the pay on delivery strategy employed by respondents' during ecommerce transactions. The results in Table 10 indicate that respondents with an income range of $\$ 151,000$ - $\$ 200,000$ used the pay on delivery platform than other respondents with a mean of 4.44 , followed by those with an income below $\$ 50,000$ with the mean 4.39 . This shows that youths who are single and earn some income often use the pay on delivery platform for all e-commerce transactions in Nigeria.

\section{Frequency and Risk Reducing Strategies}

Table 11 shows a one way ANOVA test between the frequency of online payment usage by respondents and the four risk reduction strategies influencing customers' attitude towards online payment.

TABLE 11: Frequency and Risk Reducing Strategies

\begin{tabular}{|l|c|c|c|c|c|}
\hline Between groups & Sum of Squares & df & Mean Square & F & Sig. \\
\hline POD & 10.7629 & 4 & 2.6907 & 3.67 & 0.0069 \\
\hline MBG & 2.8835 & 4 & 0.7209 & 0.74 & 0.5637 \\
\hline EWOM & 6.3059 & 4 & 1.5765 & 1.39 & 0.2395 \\
\hline INFO & 9.2484 & 4 & 2.3121 & 2.04 & 0.0918 \\
\hline
\end{tabular}

Source: Researcher's Computation, 2018

The results of the ANOVA test above shows that there is a significant between the frequency of online payment usage and pay on delivery strategy for e-commerce transactions by respondents at $5 \%$ level of significance.

To measure the strength of association (omega square, $\omega^{2}$ ) between the independent variable and the dependent variable, since there is a significant $F$, from the one way analysis of variance of the effect of the frequency of online payment usage and pay on delivery, the omega square is calculated as:

$$
\begin{aligned}
\text { Omega square }\left(\omega^{2}\right) & =\mathrm{SS}_{\mathrm{B}}-(\mathrm{K}-1) \mathrm{MS}_{\mathrm{W}} /\left(\mathrm{SS}_{\mathrm{T}}+\mathrm{MS}_{\mathrm{W}}\right) \\
& =10.76-(4-1) 0.7341 /(131.89+0.7341) \\
& =8.5577 / 132.6241=0.065
\end{aligned}
$$

The results indicated that the independent variable (frequency) accounts for approximately $6.5 \%$ of the variance in the dependent variable (pay on delivery) strategy influencing consumers' attitude towards online payment. 
Table 12: Dependent Variable: Pay on Delivery

\begin{tabular}{|lll|}
\hline Frequency & Mean & Std. Dev. \\
\hline At least once a month & 4.2241 & 0.7957 \\
\hline Once in two months & 4.3158 & 0.6619 \\
\hline I have shopped only once & 4.4348 & 0.7278 \\
\hline I want to, but it's too risky & 3.7647 & 1.3932 \\
\hline I shop always & 3.7647 & 0.8896 \\
\hline
\end{tabular}

Source: Researcher's Computation, 2018

The results in Table 12 from the summary of Scheffe's Post Hoc test indicate that the respondents who have shopped only once online used the pay on the delivery strategy more than others. This shows that respondents who uses e-commerce platform often may be employing other risk reducing strategies other than pay on delivery while transacting online.

\section{Econometric Analysis}

Ordered logistic regression

Number of obs $=170$

LR chi2(4) $=29.32$

Prob $>$ chi $2=0.0000$

Log likelihood $=-208.39427 \quad$ Pseudo R2 $\quad 0.1657$

\begin{tabular}{|llllllll|}
\hline Attitude & Coef. & Std. Err. $\mathrm{z}$ & \multicolumn{1}{l}{ P $>\mathrm{z}$} & {$[95 \%$ Conf. } & Interval $]$ \\
\hline POD & 0.2436 & 0.1769 & 1.38 & 0.016 & 0.5903 & 0.1030 & \\
\hline MBG & 0.7579 & 0.1658 & 4.57 & 0.000 & 0.4329 & 1.0829 \\
\hline EWOM & 0.2007 & 0.1467 & 1.37 & 0.171 & -0.0868 & 0.4881 \\
\hline INFO & -0.0400 & 0.1442 & -0.28 & 0.782 & -0.3225 & 0.2426 \\
\hline
\end{tabular}

Source: Researcher's Computation, 2018

\section{Hypotheses testing}

Using the ordered logistic regression, four hypotheses involving the identified risk reduction strategy and their effect on customers' attitude was tested. The aim was to identify the extent of influence that each risk reducing strategy has on customers' attitude to make payment using online platforms. The empirical results show that POD $(\mathrm{p}=0.016$, coef. 0.2436), $\mathrm{MBG}(\mathrm{p}=$ 0.000 , coef. 07579$)$ and EWON ( $p=0.171$, coef. $=0.2007)$ has a positive and significant effect on consumers attitude to make payments online. The hypothesis 1, 2 and 3 are supported by the results. This implies that consumers will continue to gain more confidence in making payments online with these risk reducing strategies featuring prominently in online shopping transactions. In contrast, informational influence $(p=0.782$, coef. $=-0.0400)$ is insignificant, and has a negative effect on consumers attitude to make payment online. There is no explanation as to why its effect on consumer attitude is insignificant in a cash-based economy, but lack of trust from the sources providing the information may be a factor. It is also possible that consumers become too familiar with the information such that even more information makes little impact on attitude.

\section{CONCLUSION}

In a cash-based economy just experiencing the influx of electronic vendors, there is a tendency for online shoppers' perceived risk to be high. Online vendors employ various risk reducing strategies to induce customers to buy and pay for a product online. There is need to understand the customers attitude towards these risk reduction strategies, and identify which one is most effective in a cash based economy.

The aim of this study was to examine the effect identified risk reducing strategy have on consumers attitude to pay online and the effect demographic variables have on the relationship 
between risk reducing strategies and consumers' attitude towards electronic payment in a cash based economy.

Four basic risk reducing strategies that are common in Nigeria were selected. They are Pay-ondelivery, Money back guarantee, Electronic word of mouth and information influence. The study made the following findings.

One, customers are favourably disposed to Pay on delivery strategy. This method is unique to Nigeria, and was adopted by online vendors to mitigate the effect of the perceived risk felt by customers. Surprisingly, money back guarantee which was highly rated in previous studies came second in ranking and information influence which is very effective in other climes, played a little role in relieving risk in Nigeria. While these methods are very useful in most advanced economies, they have proved less effective in a cash based economy. This could be explained by the fact that developing economies lack the financial structure to boost confidence in online transactions. Secondly, an economy like that of Nigeria is fraught with an alarming rate of internet fraud, poor internet facilities and regulatory agencies are poorly equipped to deal with defaulting vendors.

On the second objective, the relationship between age and POD was significant while others were insignificant. The younger the customers, the more confident they have in the POD. This may imply that the older/more experienced the customers get and the more financial independent they become; the less likely they will depend on POD.

This implies that the gender of customers has no relationship with the risk reduction strategy employed for online payments by Nigerian youth.

Finally, the study recommends that online vendors should adopt the pay-on-delivery method in a cash-based economy to smoothen the movement from traditional payment methods to online payment methods. Where financial infrastructure is lacking, pay-on-delivery, money back guarantee and encouraging more interpersonal online interaction among users will help in mitigating the risk to pay online faced by, they should also provide more money back guarantees and pay-on-delivery offers to consumers to simulate and hasten their movement from

\section{References}

Akaah, I. P., \&Korgaonkar, P. K., 1988. A conjoint investigation of the relative importance of risk relievers in direct marketing. Journal of Advertising Research. 28(4), 38-44.

Avgerou, C. (2008). Information systems in developing countries: a critical research review. Journal of information Technology, 23(3), 133-146.

Bart, Y., Shankar, V., Sultan, F., \& Urban, G. L. (2005). Are the drivers and role of online trust the same for all web sites and consumers? A large-scale exploratory empirical study. Journal of marketing, 69(4), 133-152.

Bauer, R. A. (1960). Consumer behavior as risk taking.In Cox, D. (Ed.), Risk taking and information handling in consumer behaviour (pp. 389-398).Cambridge, MA: Harvard University Press

Bhatnagar, A., Misra, S. and Rao, H. R. (2000) “On risk, convenience and internet shopping behavior, association for computing machinery," Communications of the ACM. (43)11, 98-105.

Burns, W. J., Peters, E., \&Slovic, P. (2012). Risk Perception and the Economic Crisis: A Longitudinal Study of the Trajectory of Perceived Risk. Risk Analysis, 32(4), 659-677. https://doi.org/10.1111/j.1539-6924.2011.01733.x

Cemberci, M., EmreCivelek, M., \&Sözer, E. G. (2013). The determinants of intention to shop online and effects of brand equity on e-store patronage. Journal of Global Strategic Management, 13, 125-145.

https://doi.org/10.20460/JGSM.2013715679 
Cheng, A. Y., N. R. Ab Hamid, and E. H. Cheng 2011. "Risk Perception of the E-Payment Systems: A Young Adult Perspective." In Proceedings of the 10th WSEAS International Conference on Artificial Intelligence, Knowledge Engineering and Data Bases, 121-127. Kuala Lumpur: World Scientific and Engineering Academy and Society.

Datta, P. (2011). A preliminary study of ecommerce adoption in developing countries.Information Systems Journal, 21(1), 3-32. https://doi.org/10.1111/j.1365-2575.2009.00344.x

Ejiofor, V. E., \&Rasaki, J. O. (2012). Realising the Benefits and Challenges of Cashless Economy in Nigeria: IT Perspective. International Journal of Advances in Computer Science and Technology, 1(1) Available Online at http://warse.org/pdfs/ijacst02.

Ellison, N.B., Steinfield, C. \& Lampe, C. (2007) The benefits of Facebook 'friends': social capital and college students' use of online social network sites. Journal of Computer-Mediated Communication, 12(4). Available online at: http://jcmc.indiana. edu/vol12/issue4/ellison.html (accessed on 13 November 2017).

Forsythe, S. M., \& Shi, B., 2003. Consumer patronage and risk perceptions in internet shopping.Journal of Business Research. 56(11), 867-875.

Hassan, M., Kunz, M. B., Pearson, W., \& Mohamed, F. (2006).Conceptualization and measurement of perceived risk in online shopping.Marketing. 16(1), 138-147.Retrieved from http://ebiz.bm.nsysu.edu.tw/2011/vanessa/????Perceived Risk/Conceptualization and Measurement of Perceived Risk in Online Shopping.pdf

Hamid, N.R. \& Cheng, A.Y. (2013), A risk perception analysis on the use of electronic payment systems by young adult, Information science and applications, 10 (1), 26-35.

Heeks, R. (2002). Information systems and developing countries: Failure, success, and local improvisations. The information society, 18(2), 101-112.

Huang, W., Schrank, H., \& Dubinsky, A. J. (2004). Effect of brand name on consumers' risk perceptions of online shopping. Journal of Consumer Behaviour, 4(1), 40-50. https://doi.org/10.1002/cb.156

Leeraphong, A., \&Mardjo, A. (2013). Trust and Risk in Purchase Intention through Online Social Network: A Focus Group Study of Facebook in Thailand. Journal of Economics, Business and Management, 1(4), 314-318. https://doi.org/10.7763/JOEBM.2013.V1.68

Lenhart, A. (2009) Adults and social network websites. Available online at: http://www.pewinternet.org/PPF/r/272/report_display.asp (accessed on 15 February 2010).

Liebermann, Y. and Paroush, J. (1982), "Economic aspects of diffusion processes", Journal of Economics and Business, 34, 95-100

Liebermann Y. and Stashevsky S., (2002). Perceived risks as barriers to internet and e-commerce usage. Qualitative Market Research, 5(4), 291-300,

Liaw, G. O. U., Zhu, Z. W. E., \& Lee, Y. A. O. (2005). The Effects of Risk Reduction Strategies on Consumers' Risk Perceptions and Online Purchase Intention. Pan-Pacific Management Review. 8(1), 1-37

Karoubi, B., Chenavaz, R., \& Paraschiv, C. (2016). Consumers' perceived risk and hold and use of payment instruments. Applied Economics, 48(14), 1317-1329.

Kollmann, T., Kuckertz, A., \& Kayser, I. (2012). Cannibalization or synergy? Consumers' channel selection in online-offline multichannel systems. Journal of Retailing and Consumer Services, 19(2), 186-194.

Kwahk, K.-Y., \& Ge, X. (2012). The Effects of Social Media on E-Commerce: A Perspective of Social Impact Theory. 2012 45th Hawaii International Conference on System Sciences, 1814-1823.

https://doi.org/10.1109/HICSS.2012.564

Mangold, W.G. \& Faulds, D.J. (2009) Social media: the new hybrid element of the promotion mix. Business Horizons, 52(4), 357-365.

Organisation for Economic Co-operation and Development (1999). The Economic and Social Iimpact of Ecommerce. Available at http://www.oecd.org/dataoecd/3/12/1944883.pdf, accessed on Feb. 14, 2005.

Papagiannidis, S., \& Westland, J. C. (2014). The moderating role of income on consumers' preferences and usage for online and offline payment methods. Electronic Commerce Research, 14(2), 189-213.

March, J. G., (1978). Bounded rationality, ambiguity, and the engineering of choice, Bell Journal of Economics, 9 , 587-608.

Ming-Yen Teoh, W., Choy Chong, S., Lin, B., \& Wei Chua, J. (2013). Factors affecting consumers' perception of electronic payment: an empirical analysis. Internet Research, 23(4), 465-485. https://doi.org/10.1108/IntR-092012-0199 
Mitchell, V. W., \& McGoldrick, P. J. (1996). Consumer's risk-reduction strategies: a review and synthesis. International Review of Retail, Distribution and Consumer Research, 6(1), 1-33. https://doi.org/10.1080/09593969600000001

Molla, A., \&Heeks, R. (2007). Exploring e-commerce benefits for businesses in a developing country. Information Society, 23(2), 95-108. https://doi.org/10.1080/01972240701224028

Nwankwo, O., \&Eze, O. R. (2012). Electronic Payment in Cashless Economy of Nigeria: Problems and Prospect. Journal of Management Research, 5(1), 138-151. https://doi.org/10.5296/jmr.v5i1.2650

Salam, A. F., Rao, H. R., \&Pegels, C. C. (2003). Consumer-perceived risk in e-commerce transactions. Communications of the ACM, 46(12), 325. https://doi.org/10.1145/953460.953517

Soopramanien, D. (2011). Conflicting attitudes and scepticism towards online shopping: The role of experience. International Journal of Consumer Studies, 35(3), 338-347. https://doi.org/10.1111/j.1470-6431.2010.00945.x

Sun, T. (2011). The roles of trust and experience in consumer confidence in conducting e-commerce: A crosscultural comparison between France and Germany. International Journal of Consumer Studies, 35(3), 330-337. https://doi.org/10.1111/j.1470-6431.2010.00938.x

Vos, A., Marinagi, C., Trivellas, P., Eberhagen, N., Skourlas, C., \& Giannakopoulos, G. (2014). Risk Reduction Strategies in Online Shopping: E-trust Perspective.Procedia - Social and Behavioral Sciences, 147, 418-423. https://doi.org/10.1016/j.sbspro.2014.07.122

Zilberman, D., Jin, Y., Zilberman, D., \&Heiman, A. (2014). Fit Risk : Secondhand Market versus Money-back Guarantee. University of California at Berkeley.

Yaqub, J. O. (2013). The Cashless Policy in Nigeria : Prospects and Challenges Department of Economics Department of Economics Department of Economics, 3(3), 200-212.

Yong-Hui Li and Jing-Wen Huang (2009) Applying Theory of Perceived Risk and Technology Acceptance Model in the Online

Yoo, C. W., Kim, Y. J., \& Sanders, G. L. (2015). The impact of interactivity of electronic word of mouth systems and E-Quality on decision support in the context of the e-marketplace.Information and Management, 52(4), 496-505. https://doi.org/10.1016/j.im.2015.03.001

Yu, H. C., Hsi, K. H., \& Kuo, P. J. (2002). Electronic payment systems: an analysis and comparison of types. Technology in Society, 24(3), 331-347. 